\title{
Moral concerns on tradable pollution permits in international environmental agreements
}

\author{
by \\ Johan Eyckmans ${ }^{* *}$ \\ Hogeschool-Universiteit Brussel - HUB \\ Stormstraat 2, B-1000 Brussels, Belgium \\ and \\ Katholieke Universiteit Leuven \\ Centrum voor Economische Studiën \\ and \\ Snorre Kverndokk ${ }^{* * *}$ \\ Ragnar Frisch Centre for Economic Research \\ Gaustadalléen 21, 0349 Oslo, Norway
}

June 2009

\begin{abstract}
We investigate how moral concerns about permit trading affect an endogenous pollution permit trading equilibrium, where governments choose non-cooperatively the amount of permits they allocate to domestic industries. Politicians may feel reluctant to allow permit trading and/or may prefer that abatement is undertaken domestically due to moral concerns. This will have an effect on the initial permit allocations, and, therefore, on global emissions. The impact on global emissions depends on the precise formulation of the moral concerns, but under reasonable assumptions, we show that global emissions may increase. Thus, doing what is perceived as good does not always yield the desired outcome. However, this can be offset by restrictions on permit trading when governments have moral concerns about this trade.
\end{abstract}

Keywords: Tradable emission permits, international environmental agreements, noncooperative game theory, moral motivation, identity.

JEL code: D63, Q54.

\footnotetext{
* We are indebted to comments from Kjell Arne Brekke, Carolyn Fisher, Rolf Golombek, Karen Evelyn Hauge, Carsten Helm, Karine Nyborg, Alistair Ulph and other participants at the Frisch Centre Klækken seminar (May 2007), the CAS Workshop in Asker (August 2007), the public economics seminar in Leuven (April 2008), EAERE in Gothenburg (June 2008), RFF (May 2009) and NORKLIMA kick-off in Drøbak (June 2009). Kverndokk is also indebted to the hospitality of Katholieke Universiteit Leuven, Department of Economics, and Johns Hopkins University, SAIS while working on this paper.

*** Johan.Eyckmans@HUBrussel.be

*** Corresponding author: Snorre.Kverndokk@ frisch.uio.no
} 


\section{Introduction}

Economists typically prefer trade in pollution permits to conventional, non marketbased environmental policy instruments, as both in theory (Montgomery, 1972) and in practice (Schmalensee et al., 1998), market-based policy instruments have been shown to foster cost effectiveness. However, many non-economists such as environmental organisations and political parties have objected against permit trade. Some consider it a way of avoiding one's obligations, to pay others to clean up, or to pay indulgence, see Goodin (1994). ${ }^{1}$

Several existing multinational tradable permit schemes contain restrictions on permit trading. These may have been introduced as a consequence of signatories being reluctant to allow full trading. ${ }^{2}$ In the Kyoto protocol on greenhouse gas emissions for instance, trade in pollution permits is allowed, but only as a supplement to national mitigation. ${ }^{3}$ Also in the European Emission Trading Scheme (ETS), access to buying emission reductions in third party countries (JI - Joint Implementation for economies in transition and CDM - Clean Development Mechanism for developing countries) is limited. ${ }^{4}$ Thus, the cost-effective volume of trade may not be within reach.

In this paper we will study the implications of moral considerations about permit trading in an international cap-and-trade market. These moral considerations are assumed to play a role only in the governments' decision making process; not in the profit maximization objective of the permit trading firms. In a first stage of the model, governments are assumed to negotiate on national emission targets at an international forum. The emission ceilings are allocated freely to the national industries, which can trade the permits in an international and competitive pollution permit market in the second stage of the model. The set up is similar to the one of Helm (2003) and implies that the overall emissions, and hence the total number of pollution permits, is

\footnotetext{
${ }^{1}$ Carsten Helm pointed out to us that "Luftverschmutzungsrechte" - tradable air pollution permits - was on place 3 in the 2004 voting for the "Unwort des Jahres" (ugliest word of the year) in Germany, see http://www.unwortdesjahres.org/.

${ }^{2}$ Competing explanations based on market power arguments have also been put forward, see Ellerman and Wing (2000).

${ }^{3}$ Article 6.1 of the original Kyoto Protocol text states "The acquisition of emission reduction units shall be supplemental to domestic actions for the purposes of meeting commitments under Article 3". However, later meetings of the Conference of the Parties ( $\mathrm{CoP}$ ) have not been able to find a consensus on a more precise or quantitative meaning of this supplementarity requirement.

${ }^{4}$ More details on the latest proposed changes in the EU ETS $3^{\text {rd }}$ phase (2013-2020) can be found at http://europa.eu/rapid/pressReleasesAction.do?reference=MEMO/08/796. As by May 2009, it is clear that access to CDM and JI projects will not be unlimited.
} 
determined endogenously and not given exogenously as is the case in most of the existing literature on tradable permit markets. Our model is particularly suited to describe the ongoing negotiation process to forge a follow up agreement to the Kyoto Protocol, which should culminate in a new climate treaty by the end of 2009. Most likely, a new agreement will combine national emissions targets with provisions for emissions trading.

Moral considerations are captured in our model by means of identity effects (Akerlof and Kranton, 2000, 2005; Brekke, et al., 2003). Governments are assumed to care about the identity of their nation as this reflects the views of their voters. There may be different reasons for moral concerns as discussed below, and we focus on two ways to specify identity effects, that we think capture many arguments that have been raised. First, we assume that a nation's identity is negatively affected by its net permit trade volume. This reflects the idea that some do not like trading pollution permits simply because they believe one should not trade in an essentially non-desirable item like licences to pollute. But, at the same time, we assume that countries are willing to trade off the better identity against benefits from exchanging permits.

In our second formulation of moral considerations, we assume countries' identities depend on their actual abatement effort at home. Thus, they benefit in identity terms from abating at home instead of buying emission reductions elsewhere. This is specified as the identity depending negatively on the gap between countries' actual and ideal emission levels, the latter reflecting what they think they ideally should do. This formulation captures concern for the state of the global environment and one's own responsibility for it.

We study how moral considerations may affect global emissions in an endogenous permit trading equilibrium, and we find that the effect on global emissions depends on how these concerns are specified. With distaste for permit trading, moral considerations will most likely lead to higher, instead of lower, global emissions in an international climate agreement with permit trading. The reason is that on average, permit importing countries have a stronger incentive to over allocate their domestic industries to reduce permit purchases compared to the incentive of permit exporting countries to under allocate theirs. However, if the concern of countries is based on a preference for domestic abatement and global responsibility, global emissions will go down. This conclusion is based on an equal concern in all countries, which will 
probably not be the case. If only a few countries share this concern, the positive environmental effect may be rather small. Both these results show that good intentions do not always yield the desired results.

While restrictions on permit trading as introduced in the Kyoto Protocol and the ETS, may be bad for the environment as they increases the costs of reaching an emissions target, and, therefore, the incentive to join a treaty, we show that such restrictions may actually reduce global emissions when governments are morally concerned about trading permits. The reason is that the incentive of permit importers to over allocate domestic industries to reduce permit purchase has been reduced. Thus, if the restrictions result from reluctance to trade, they may actually be good for the environment.

The paper is organised in the following way. We first discuss possible reasons behind the reluctance to trade pollution permits. In section 3 , we present the model, while section 4 derives conclusions on how moral concerns about emission permit trading change governments' behaviour in the permit trading market and, therefore, global emissions. Section 5 studies the impacts on global emissions from restrictions on buying permits, and the final section concludes.

\section{Ethical reasoning, norms and identity}

In economic theory, it is assumed that most goods can be bought or sold in a market. However, this may not always be the case and distaste, or even repugnance, for certain transactions may be a real constraint in many markets, see Roth (2007) for a survey. $^{5}$ This situation can be described as if there exists a norm against trading certain goods. A norm is defined as a standard of right or wrong, and in all cultures there are goods that are considered to be "priceless" or "sacred" in such a way that we cannot set a price on them. Examples may be life, freedom, love, friendship, children, religion, democracy and the environment. Some of these goods are called taboo goods (Fiske and Tetlock, 1997) where a taboo is defined as a particularly powerful kind of normative prohibition. Taboos are meant to protect individuals and societies "from behaviour defined or perceived to be dangerous" (Tannenwald, 1999), and breaking a taboo usually results in social sanctions or repercussions. However, there are also

\footnotetext{
${ }^{5}$ Frank (1985), chapter 10, also gives several examples of why trade in certain goods should not be allowed.
} 
tradable goods for which there is a social norm against it being freely traded, but for which this norm is not as strict as for taboo goods. Examples may be legalized prostitution, body organs and military duty (Bénabou and Tirole, 2007; Roth, 2007). Some kinds of transactions are considered repugnant in some times and places, but not in others, thus the boundaries between the secular and the sacred are evolving over time. Slavery used to exist in large parts of the world, but is now repugnant and illegal in most places. But there have also been more positive attitudes to some goods over time such as life insurance (Zeliner, 1999) and legalized prostitution.

Markets for pollution permits has been recognised by several authors as a case in which there may exist some reluctance or even repugnance against transactions, see, e.g., Goodin (1994), Bénabou and Tirole (2007) and Roth (2007). But why may there be reluctance against trade in pollution permits? We can identify several possible reasons for this, some of which are based on arguments rooted in a more procedural view of justice, and others in a more consequentialist ethics framework.

Based on a procedural justice approach, on can argue that industrialised countries have created the global warming problem, and that it is their duty to reduce the consequences of it, even if this does not minimise overall costs of taking action. This can be used as an argument against developing countries selling permits to industrialised countries because the permit trade would not lead to abatement in the countries responsible for the problem. Another argument is based on unfair background conditions (see Kverndokk, 1995, and Eyckmans and Schokkaert, 2004). Even if two parties agree to trade permits, the trade may not be justified on ethical grounds. A voluntary agreement between two parties is not necessary fair if is entered into conditions that are not fair (Pogge, 1989). Background justice is not preserved when some participant's basic rights, opportunities or economic positions are grossly inferior. ${ }^{6}$ Under the Kyoto Protocol, for instance, some may argue that this is the case for some CDM contracts, as this is a trade between poor and rich countries. ${ }^{7}$

Another line of arguments hinges on consequentialist ethics. Standard economic analysis is basically about consequences and if the consequences of a particular policy are positive (i.e., increased welfare), economists recommend it. This is the case with

\footnotetext{
${ }^{6}$ Some examples can be kidney trade or an agreement between a prostitute and her/his customer.

${ }^{7}$ Some argue that it is not fair that the developed countries take all the "low hanging fruits" and the developing countries are left with the more expensive mitigation options in a possible future agreement.
} 
emission permits. The basic argument in favour of permit trade is that it is costeffective (Montgomery, 1972). Parties involved in permit trade would get lower abatement costs than if they had to mitigate the emissions within their geographical boundaries. Thus, cost-savings will be welfare improving, everything else equal. One possible explanation of the resistance to permit trade is, therefore, that welfare improvements following from permit trade have not been communicated well enough, i.e., this point of view is based on lack of information. ${ }^{8}$

However, explanations based on allegedly negative consequences of a permit market, may also be plausible. Buying CDM quotas, i.e., greenhouse gasses pollution permits in countries that did not subscribe to binding emission limits in the Kyoto Protocol, may have adverse effects based on lack of an emission baseline, moral hazard, lack of incentives to undertake emissions reductions by the developing countries, transaction costs and carbon leakages. As a result, CDM projects may not fully offset emissions, see Rosendahl and Strand (2009). Hot air, meaning that some countries receive an initial emission quota allocation that exceeds their actual emissions, has also been mentioned as a reason to avoid emission trading as trading hot air will not reduce emissions.

Abating at home instead of buying emission permits may also be seen as a better policy based on consequences. Arguments that have been raised in this debate are the positive spillover effects of technology development by national abatement as well as the ancillary benefits (reduction in local emissions, traffic accidents, congestion etc.) of abating at home. It is further argued that unilateral abatement may lead to similar behaviour by other countries, it may affect positively the negotiation climate in the international policy arena, and it may reduce the conflict of interest within a country as it actually shows the true costs of abatement, a cost that economic agents have an incentive to exaggerate; see Hoel (1991) and Golombek and Hoel (2004).

Also environmental justice, related to race and ethnicity, has been used as an argument for abating at home related to the ancillary benefits argument above (see, e.g., Kverndokk and Rose, 2008, for a survey). Many toxic waste sites are located in or near minority neighborhoods, and this has led to opposition to emissions trading.

\footnotetext{
${ }^{8}$ One example pointed out to us by Alistair Ulph is as follows. If a country has extremely high marginal abatement costs (in the limit infinite: i.e., it cannot abate) then wanting to do all the abatement at home is just not sensible; it would seem more appropriate, for a country to use its resources to pay a country which can abate cheaply to do so.
} 
Although the location of greenhouse gas reduction does not matter because it is a globally mixed pollutant, reduction of co-pollutants (e.g., sulfur oxides, particulates, air toxics) does. Minority neighborhoods might not gain a potential reduction of these co-pollutants if the local emitters buy permits and, therefore, do not take actions to lower emissions of all pollutants at home.

The discussion above provides arguments, based on both procedural fairness and consequentialist ethics, against permit trading. We summarize this discussion by reducing it to two basic statements that we will use to formalize moral concerns:

1) People might dislike permit trading, and

2) People might prefer to do abatement at home.

The first statement is weaker than the second as reluctance to trade permits does not necessary mean that countries care about the environment. However, reasons to avoid trading are often based on a preference for environmental values, and in the second claim, the major motivation is to save the environment, independent of international agreements and quota trade. We do not claim that these statements are true or that there are good ethical arguments against permit trading. Instead, we take an agnostic stand and take these arguments as given as we think they describe some of the reluctance observed in the political debate on permit trading. Also note that in the following, we assume that governments perform the moral reasoning on behalf of their voters, so that moral concerns by the people of a nation are reflected in government's policies. If a substantial share of voters has moral concerns about permit trading, it will be reflected in the government's decision if politicians care about their re-election chances.

The statements above may constitute a norm against trading pollution permits. Norms are closely related to the preservation of identity, and by modelling a norm against permit trade, we build on the theory of identity and moral motivation (Akerlof and Kranton, 2000, 2005; Brekke, et al., 2003). In this way we can model both the reluctance to trade with pollution permits, and given that the agent does not follow the norm, the wish to reduce the trade even if it is economically profitable. As the reasons for reluctance to trade may be based on both procedural fairness as well as consequences, we do not try to endogenise the norm in the model, meaning that we do not determine why a society chooses a certain norm against pollution permit trading. 


\section{The endogenous permit market allocation model}

Our framework is based on Helm (2003) who presents a model of international emissions trading in which countries choose the amount of permits they allocate to their domestic industry in an endogenous and non-cooperative way. ${ }^{9}$ We expand Helm's model by introducing moral concerns (identity considerations). Countries are assumed to be reluctant to trade emissions permits and/or may dislike the fact that they emit more than what they think they ideally should do.

The basic building blocks of the model are as follows. There are $n$ countries or governments engaged in negotiating a future international environmental agreement including provisions for pollution permit trading. The governments represent the view of their voters who are, to some extent, reluctant to trade permits. However, they are also willing to trade if the benefits from trade are large enough. As in Helm (2003), we make the assumption that the permit-trading regime is established only by unanimous approval of all countries. ${ }^{10}$

In the first stage, governments choose non-cooperatively their initial emissions allocation. This set-up resembles closely the reality of international climate negotiations, in particular in the run up to the 1997 Kyoto Protocol and in the negotiations on a follow up agreement. Another example is the ETS where EU member states had to draft National Allocation Plans (NAPs) suggesting a permit allocation for all installation covered by the ETS directive on their territory for Phase 1 (2005-2007) and Phase 2 (2008-2012). In contrast to most of the literature on national emission permit schemes, the overall number of permits cannot be assumed to be exogenous in an international context.

In the second stage of the game, individual firms trade emissions in a competitive permit market. We assume that they obey the emission ceiling and that they maximize their private profit only. Thus, firms do not have moral concerns about trading. ${ }^{11}$

This game is solved by backward induction, i.e., we start be solving the second stage.

\footnotetext{
${ }^{9}$ For other applications of the model, see Holtsmark and Sommervoll (2008) and Carbone et al. (2009).

${ }^{10}$ Allowing for endogenous coalition formation would substantially complicate the analysis, as the countries are not symmetric in our analysis. Symmetric or homogeneous countries is a common assumption in studies of coalition formation, see, e.g., Barrett (2005), but would be inappropriate in our case since the difference between countries is essential in the analysis of pollution permit trading.

${ }^{11}$ This is consistent with Siebert (1992, p. 130) and Rauscher (2006) who argue that a firm spending resources on social activities not rewarded by the market will not remain competitive and will be driven out of the market. However, if firms have market power, non-profit motives can survive.
} 


\subsection{Stage 2: Firms trading emissions}

In every country $i \in N=\{1,2, \ldots, n\}$ there is a large number of identical firms that maximizes profits due to emissions, $\pi$, taking as given the emissions trading scheme:

$$
\max _{e_{i}} \pi_{i}\left(e_{i} ; p, \omega_{i}\right)=B_{i}\left(e_{i}\right)+p\left[\omega_{i}-e_{i}\right]
$$

Let $\omega_{i} \geq 0$ be the initial allocation of permits to the representative firm in country $i$ and assume that permits are allocated for free. For simplicity, we set the emissions of one country equal to the emissions of its representative firm, $e_{i} \in\left[0, \bar{e}_{i}\right]$, where $\bar{e}_{i}$ is business as usual (BAU) emissions, i.e., emissions in absence of an international treaty and any moral considerations. This is the maximum emissions that a country will emit. ${ }^{12}$ Emissions can be traded at a given market price $p$. Firms choose emissions in order to maximize profits, i.e., the sum of benefits and net permit trade revenues. The benefits of emissions, $B_{i}$, can be interpreted as a production function. Production requires input of carbon emissions, and is assumed increasing and strictly concave in emissions: $B_{i}^{e} \geq 0$ and $B_{i}^{e e}<0$. In the Appendix, the formal properties of the benefit function are derived from the standard properties of an emission abatement cost function.

From the first-order condition for profit maximization, we can derive the demand for emissions:

$$
B_{i}^{e}\left(e_{i}\right)=p \Rightarrow e_{i}=E_{i}(p)=\left(B_{i}^{e}\right)^{-1}(p)
$$

Profit maximizing behaviour by firms leads to cost-effectiveness; marginal benefits of emissions are equalised across firms. Thus, this condition is valid even if countries have moral arguments against permit trading as such considerations are not taken into account by the competitive firms.

Comparative statics of this expressions shows that emissions are decreasing in the permit price:

$$
B_{i}^{e e} d e_{i}=d p \quad \Rightarrow \frac{\partial e_{i}}{\partial p}=E_{i}^{p}=\frac{1}{B_{i}^{e e}}<0
$$

\footnotetext{
${ }^{12}$ Note that will moral concerns on abatement at home, emissions will be less than $\bar{e}_{i}$ even in the absence of a climate treaty, see section 4.4.
} 
Using first-order condition (2), we can define a "net supply of permits" function that is increasing in the price of permits:

$$
S_{i}(p)=\omega_{i}-E_{i}(p) \quad \text { with } \quad \frac{\partial S_{i}}{\partial p}=S_{i}^{p}=-E_{i}^{p}>0
$$

A permit market equilibrium defines a price level such that total net supply of permits is nonnegative:

$$
p^{o} \quad \text { such that } \sum_{j \in N} S_{j}\left(p^{o}\right)=\sum_{j \in N}\left[\omega_{j}-E_{j}\left(p^{o}\right)\right] \geq 0
$$

This market equilibrium condition implicitly defines a price function mapping a vector of emission allocations $\boldsymbol{\omega}$ into the market clearing price level: $p^{o}=\rho(\boldsymbol{\omega})$. We assume that the marginal benefit functions are such that for every vector of emission allocations, there exists a unique equilibrium permit price. ${ }^{13}$ The permit price function can be shown to be decreasing in the initial allocations of permits to a country.

$$
\rho^{\omega_{i}}(\boldsymbol{\omega})=\frac{\partial \rho}{\partial \omega_{i}}=\frac{d p^{*}}{d \omega_{i}}=\frac{1}{\sum_{j \in N} E_{j}^{p}}<0
$$

Hence, in accordance with standard economic intuition, higher allocations of permits lead to a decrease in the equilibrium permit price.

\subsection{Stage 1: Governments choosing initial permit allocations}

Given the smoothly working permit market in stage two, governments negotiate in stage one on the initial allocation of permits, and we assume that they choose the number of permits $\omega_{i}$ as to maximize the following national welfare function:

$$
W_{i}\left(e_{i}, \omega_{i} ; \bar{\omega}_{-i}\right)=B_{i}\left(e_{i}\right)+p\left[\omega_{i}-e_{i}\right]-D_{i}\left(\omega_{i}+\bar{\omega}_{-i}\right)+I_{i}\left(e_{i}, e_{i}^{S}, \omega_{i}\right)
$$

The function $D_{i}$ denotes pollution damages incurred in country $i$. These damages are convex in global emissions, defined by the total amount of permits distributed (country $i$ 's permits are $\omega_{i}$, while all other countries' emission permits are denoted by $\left.\omega_{-i}\right)$. Thus, the environmental problem is caused by a uniformly mixing pollutant as

\footnotetext{
${ }^{13}$ If more permits would be allocated than the net demand for emissions, we assume that the equilibrium price is zero: $\sum_{j \in N} \omega_{j}>\sum_{j \in N} E_{j}(0) \Rightarrow p^{o}=0$.
} 
in the case of global warming. We assume that country $i$ maximizes its welfare, taking as given the permit allocations by all other countries $\left(\omega_{-i}=\bar{\omega}_{-i}\right)$. Hence, we are looking for a Nash equilibrium in permit allocations among national governments.

Our set-up is similar to the model introduced by Helm (2003). However, in addition to the approach by Helm, we assume that countries have moral concerns about permit trading defined as an identity, $I_{i}$, which adds positively to their welfare function. Identity is usually defined as a person's self image - as an individual or as a part of a group (Akerlof and Kranton, 2005). Identity has been recognised as important for individual behaviour in fields as social psychology and sociology, but has only recently been adopted in formal economic models. In this paper we define a country's moral concerns in the same way as the identity of an individual as governments perform the moral reasoning on behalf of their voters.

The model also bears some resemblance to the literature on voluntary provision of public goods, see Bergstrom et al. (1986), and in particular to the strand of literature on the so-called "warm glow of giving", see Andreoni (1990). In this literature, economic agents care about the overall level of the public good and feel good about contributing a positive amount to its provision. One can interpret this warm glow effect as a positive identity effect (see Brekke et al., 2003). However, in our model, private contributions, in the sense of low allocation of pollution permits to one's domestic industry, may lead to a cold feeling instead of a warm glow as this increases the incentives for firms to enter the permit trading market and buy large amounts of permits.

Based on the statements made in section 2, the moral concern (identity) of a country is a function of it's actual emissions, $e_{i}$, it's permit allowances $\omega_{i}$ as well as it's ideal emissions, $e_{i}^{S}$. The latter is defined as the emission level that the country would like to aim for based on ethical reasoning. This ideal is considered exogenous. We return to this in section 4 .

Using the notation introduced before, we can write the welfare function of country $i$, taking into account the competitive permit trading in stage two, as:

$$
\begin{aligned}
W_{i}\left(\omega_{i}, \omega_{-i}\right)= & B_{i}\left(E_{i}(\rho(\boldsymbol{\omega}))\right)+\rho(\boldsymbol{\omega})\left[\omega_{i}-E_{i}(\rho(\boldsymbol{\omega}))\right] \\
& -D_{i}\left(\omega_{i}+\omega_{-i}\right)+I_{i}\left(E_{i}(\rho(\boldsymbol{\omega})), e_{i}^{S}, \omega_{i}\right)
\end{aligned}
$$


Each country wants to set its initial permit allocation, $\omega_{i}$, in order to maximize its welfare defined by expression (8), where the strategy space for every player is $\omega_{i} \in\left[0, \bar{e}_{i}\right]$. The first-order condition for an interior solution is, therefore, ${ }^{14}$ where $\Delta I_{i}$ is the change in identity for a change in $\omega_{i}$ :

$$
B_{i}^{e} E_{i}^{p} \rho^{\omega}+\rho^{\omega}\left[\omega_{i}-E_{i}\right]+\rho\left[1-E_{i}^{p} \rho^{\omega}\right]-D_{i}^{\omega}+\Delta I_{i}=0
$$

Using the first-order condition $B_{i}^{e}=\rho$ of competitive permit trading among firms in stage 2 (eq. (2)), the following condition should be satisfied for all countries $i \in N$ :

$$
\rho^{\omega}\left[\omega_{i}-E_{i}\right]+\rho-D_{i}^{\omega}+\Delta I_{i}=0
$$

The first term on the left hand side (LHS) is the effect of additional permit allocations on the emission trading revenue through the effect on the permit price. A more generous permit allocation is beneficial for permit importers (the market price goes down), while a more restricted permit allocation is beneficial for permit exporters (the market price goes up). We label this effect the strategic permit trading effect.

The second term is the direct price effect of a more generous permit allocation. Every additional permit is worth the prevailing market price $\rho$. The third term stands for the additional pollution damage effect caused by a more generous permit allocation. More permits lead, ceteris paribus, to higher global emissions and hence higher pollution damages. This effect is therefore negative. Finally, the last term captures the change in the moral concerns of extra permits. This effect can be positive or negative depending on the precise specification of the identity function.

Rearranging (10) and using again the firms' profit maximizing first-order condition $B_{i}^{e}=\rho$, we obtain:

$$
B_{i}^{e}=D_{i}^{\omega}-\rho^{\omega}\left[\omega_{i}-E_{i}\right]-\Delta I_{i}
$$

Hence, every country chooses an initial permit allocation such that its marginal benefit from the last ton of emissions equals individual marginal damages, corrected for a strategic permit trade effect and an identity effect.

\footnotetext{
14 All variables and functions are evaluated in the Nash equilibrium of permit allocations, i.e., the permit allocations of other countries are taken as exogenous.
} 


\section{Different formulations of nations' moral concerns}

\subsection{Reluctance to trade}

So far we have not specified the identity function. Let us consider the two statements on moral concerns from section 2: Countries might dislike permit trading, and countries might prefer to do all the abatement at home. However, for ease of exposition, we study the two statements separately before combining them.

We first focus on the statement that countries dislike permit trading. Assume a symmetric formulation of reluctance to trade, i.e., countries dislike both selling and buying permits:

$$
I_{i}\left(e_{i}, \omega_{i}\right)= \begin{cases}-F_{i}-\delta\left[\omega_{i}-E_{i}(\rho(\omega))\right]^{2} & \text { if } \omega_{i} \neq E_{i}(\rho(\boldsymbol{\omega})) \\ 0 & \text { otherwise }\end{cases}
$$

Involvement in permit trading represents a cost, both for buyers and sellers, due to the fact that one does not act in accordance with one's moral conviction. This loss in identity consists of a fixed cost independent of the amount of permits traded, and a variable cost. The fixed cost, $F_{i}>0$, is the loss of going from one regime to another, here represented by going from a non-trade regime to a trading regime. However, the volume of trade also matters. If a country decides to trade, it feels less comfortable the higher the volume of permit trading is when $\delta>0 .{ }^{15}$ An example can be the supplementary condition in the Kyoto Protocol as well as recent political discussions in Norway on setting a limit on how much one can reduce abatement abroad. Finally, note that this identity function has a maximum at zero without emissions trading.

The specification of the moral concerns, both the fixed and the variable term represent costs of trading and thus lower welfare in the trading system compared to when moral concerns are not present. This shares similarities with a permit trade system with transaction costs as in Stavins (1995). With transaction costs, the volume of trade is lower and welfare is lower compared to a system without such costs. Also the initial allocation of permits may affect the outcome of trading. However, moral considerations affect permit trading differently than transaction costs in several

\footnotetext{
${ }^{15}$ In the case where $\delta=0$, i.e., there is an identity cost of not following the norm, which is independent on the volume of trade as long as the volume is positive, we will actually get the same first order conditions as when identity does not matter, i.e., $\Delta I_{i}=0$.
} 
respects. First, the fixed identity term affects the decision whether the country wants to take part in the permit trading market, and second, the endogenous part of the identity function affects the allocation of initial allowances as countries do not want the allocations to be very different from actual emissions. However, for a given level of aggregated allowances (global emissions target), the outcome of trading is not affected by the initial allowance allocation. In our model, firms face no transaction costs in trade so they trade cost-effectively, i.e., marginal abatement costs among sources are equal. This is not the case in models with transaction costs as these costs are usually modelled as a function of the volume of trade.

Using this explicit identity function, we can derive the following lemma:

\section{LEMMA 1}

If countries are reluctant to trade permits, and if identity is symmetric, then:

\section{- $\quad$ if country $i$ is a permit seller $\left(\omega_{i}>E_{i}\right)$ it follows that $B_{i}^{e}>D_{i}^{e}$;}

- $\quad$ if country $i$ is a permit buyer $\left(\omega_{i}<E_{i}\right)$ it follows that $B_{i}^{e}<D_{i}^{e}$.

This means that sellers underallocate and buyers overallocate emissions compared to a situation without permit trading and without moral concerns.

Proof: The change in identity from a marginal increase in $\omega_{i}$ is given by: $\Delta I_{i}=-2 \delta\left[1-E_{i}^{p} \rho^{\omega}\right]\left[\omega_{i}-E_{i}\right]$. This change is positive for permit buyers and negative for permit sellers for the symmetric identity function because $0 \leq E_{i}^{p} \rho^{\omega}=E_{i}^{p} / \sum_{j \in N} E_{j}^{p} \leq 1$. It follows from (11) that:

$$
\begin{aligned}
B_{i}^{e}-D_{i}^{e} & =-\rho^{\omega}\left[\omega_{i}-E_{i}\right]+2 \delta\left[1-E_{i}^{p} \rho^{\omega}\right]\left[\omega_{i}-E_{i}\right] \\
& =\left[\omega_{i}-E_{i}\right] \underbrace{\left[-\rho^{\omega}+2 \delta\left[1-E_{i}^{p} \rho^{\omega}\right]\right]}_{+}
\end{aligned}
$$

and therefore $B_{i}^{e} \lesseqgtr D_{i}^{e}$ if $\omega_{i} \lesseqgtr E_{i}$.

Q.E.D.

The lemma says that permit sellers allocate permits so that the marginal benefit from emissions is higher than the marginal damage, while it is the other way around for permit buyers. The intuition is as follows. Net permit selling countries tend to under allocate their domestic firms, yielding marginal benefit from emissions in excess of 
marginal costs, as this makes permits scarce and drives up the equilibrium market price. In addition, the under allocation has positive identity effects as the volume of trade goes down and the gap between permit allocation and actual emissions shrinks. On the other hand, net permit buying countries tend to over allocate their domestic firms because this makes permits more abundant and lowers the market price. Further, the same identity mechanism as described for sellers is also valid for buyers; over allocating permits has positive identity effects as the volume of trade goes down. Summarizing, the moral concerns, if they only stem from reluctance to trade, strengthen the results obtained by Helm (2003). They reinforce the strategic trade incentives for both sellers and buyers of permits. This proves to be a useful result for the remainder of the paper.

\subsection{Asymmetric reluctance to trade}

How does the introduction of moral concerns affect the global amount of permits issued into the market? We start with a simple case based on the fact that the discussion on the acceptability of permit trading is mainly a topic in countries that are potential permit buyers. This means that the identity function is asymmetric, where countries only suffer an identity loss if they buy permits:

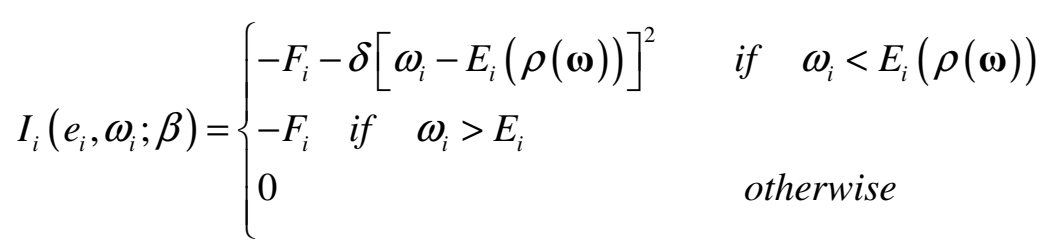

\section{PROPOSITION 1}

If only buyers are reluctant to trade (asymmetric identity function), then every individual country will emit more and global emission will be higher than in the endogenous permit allocation equilibrium without moral concerns.

Proof: The first-order conditions for governments issuing permits are different for permit importers $\left(\omega_{i}<E_{i}\right)$ and exporters $\left(\omega_{i} \geq E_{i}\right)$, see $(11)$ :

$$
\left\{\begin{array}{l}
B_{i}^{e}-D_{i}^{e}+\rho^{\omega}\left[\omega_{i}-E_{i}\right]-2 \delta\left[1-E_{i}^{p} \rho^{\omega}\right]\left[\omega_{i}-E_{i}\right]=0 \quad \text { if } \quad \omega_{i}<E_{i} \\
B_{i}^{e}-D_{i}^{e}+\rho^{\omega}\left[\omega_{i}-E_{i}\right]=0 \quad \text { if } \quad \omega_{i} \geq E_{i}
\end{array}\right.
$$


Summing over both types of countries and using the market clearing condition from (5), it follows that:

$$
\sum_{j \in N} B_{j}^{e}-\sum_{j \in N} D_{j}^{e}-2 \delta \sum_{j \in N} \min \left\{0, \omega_{j}-E_{j}\right\}\left[1-E_{j}^{p} \rho^{\omega}\right]=0
$$

Assuming, in contrast to the claim in the proposition, $\omega_{N}^{I}<\omega_{N}^{o}$ and using the convexity of the damage functions, it follows that: $\sum_{j \in N} D_{j}^{e}\left(\omega_{N}^{I}\right)<\sum_{j \in N} D_{j}^{e}\left(\omega_{N}^{o}\right)$. Summing over the appropriate first-order conditions for both equilibria, see (10), it can be shown that (recall that $0 \leq\left[1-E_{j}^{p} \rho^{\omega}\right] \leq 1$ ):

$$
\rho^{I}-\rho^{o}<\frac{2 \delta}{n} \sum_{j \in N} \min \left\{0, \omega_{j}-E_{j}\right\}\left[1-\rho^{\omega} E_{j}^{p}\right]<0
$$

Hence, the equilibrium permit price would be lower with asymmetric moral concerns than without. Given that the equilibrium price function is decreasing in the global permit allocation, we get $\omega_{N}^{I}>\omega_{N}^{o}$, which contradicts the initial assumption. Therefore, $\omega_{N}^{I} \geq \omega_{N}^{o}$, and moral concerns will lead to higher global emissions than without such concerns.

As we have shown that the equilibrium permit price will be lower with asymmetric moral concerns than without, every country's representative firm will emit more: $B_{i}^{e}\left(E_{i}^{I}\right)=\rho^{I}<\rho^{o}=B_{i}^{e}\left(E_{i}^{o}\right) \Rightarrow E_{i}^{I}>E_{i}^{o}$ due to concavity of the benefit functions.

\section{Q.E.D.}

The proposition is intuitively clear. From Lemma 1 we know that permit buyers have an incentive to over allocate their domestic industries because of 1) strategic trade considerations (driving down the equilibrium permit price), and 2) moral concerns (over allocating domestic firms reduces the amount of permits that has to be imported). Since only buyers' moral concerns are taken into account in the asymmetric identity function, global emissions in the international Nash equilibrium will be higher than in the scenario without such considerations. 


\subsection{Symmetric reluctance to trade}

We now turn to the more complicated case where both permit importers and exporters dislike permit trading, i.e., the symmetric identity function. In order to find the global effect, we summarise all countries first-order conditions based on (10) and $\Delta I_{i}=-2 \delta\left[1-E_{i}^{p} \rho^{\omega}\right]\left[\omega_{i}-E_{i}\right]$, to obtain:

$$
\begin{aligned}
& \sum_{j \in N}\left\{\rho^{\omega}\left[\omega_{j}-E_{j}\right]+\rho-D_{j}^{e}-2 \delta\left[\omega_{j}-E_{j}\right]\left[1-E_{j}^{p} \rho^{\omega}\right]\right\}=0 \\
& \Rightarrow \rho^{\omega} \sum_{j \in N}\left[\omega_{j}-E_{j}\right]+n \rho-\sum_{j \in N} D_{j}^{e}-2 \delta \sum_{j \in N}\left[\omega_{j}-E_{j}\right]+2 \delta \rho^{\omega} \sum_{j \in N}\left\{\left[\omega_{j}-E_{j}\right] E_{j}^{p}\right\}=0 \\
& \Rightarrow n \rho-\sum_{j \in N} D_{j}^{e}+2 \delta \rho^{\omega} \sum_{j \in N}\left[\omega_{j}-E_{j}\right] E_{j}^{p}=0
\end{aligned}
$$

Hence,

$$
n \rho=\sum_{j \in N} D_{j}^{e}-2 \delta \rho^{\omega} \sum_{j \in N}\left[\omega_{j}-E_{j}\right] E_{j}^{p}
$$

As the following result shows, the outcome depends on the "balance of power" between permit exporters and importers. ${ }^{16}$

\section{PROPOSITION 2}

If countries are reluctant to trade permits, identity is symmetric, and $\sum_{j \in N}\left[\omega_{j}-E_{j}\right] E_{j}^{p}>(<) 0$, global emissions will be lower (higher) and every country will emit less (more) than without moral concerns.

Proof: Assume the claim is false, i.e., $\sum_{j \in N}\left[\omega_{j}-E_{j}\right] E_{j}^{p}>0$ and $\omega_{N}^{I}>\omega_{N}^{o}$, where $\omega_{N}$ is global emissions and top script $I$ and $O$ refers to the equilibrium with moral concerns and without such concerns respectively. Because of convexity of the damage functions if follows that: $\sum_{j \in N} D_{j}^{e}\left(\omega_{N}^{I}\right)>\sum_{j \in N} D_{j}^{e}\left(\omega_{N}^{o}\right)$. Using (14) and the appropriate condition when there is no identity function (i.e., the second term of the right hand side of (14) is equal to zero), it is easily shown that:

\footnotetext{
${ }^{16}$ Note that in the following propositions we do not do comparisons to a first best social optimum as in general the first best solution with and without moral concerns would differ. One exception is the first best solution in section 4.4 where the two solutions coincide.
} 


$$
\begin{gathered}
n \rho^{I}+2 \delta \rho^{\omega} \sum_{j \in N}\left[\omega_{j}-E_{j}\right] E_{j}^{p}>n \rho^{o} \\
\Downarrow \\
\rho^{I}-\rho^{o}>\left[\frac{-2 \delta \rho^{\omega}}{n}\right] \sum_{j \in N}\left[\omega_{j}-E_{j}\right] E_{j}^{p}>0
\end{gathered}
$$

Hence, the equilibrium permit price with moral concerns would be higher than the price without such concerns. Given that the equilibrium price is decreasing in the global permit allocation, $\omega_{N}^{I}<\omega_{N}^{o}$, which contradicts the initial assumption.

Finally, as we have just shown that if $\sum_{j \in N}\left[\omega_{j}-E_{j}\right] E_{j}^{p}>0$, global emissions will be lower and, hence, the equilibrium price of permits will be higher in case of moral concerns and, therefore, every country's representative firm will emit less: $B_{i}^{e}\left(E_{i}^{I}\right)=\rho^{I}>\rho^{o}=B_{i}^{e}\left(E_{i}^{o}\right) \Rightarrow E_{i}^{I}<E_{i}^{o}$ due to concavity of the benefit functions.

\section{Q.E.D.}

Hence, if $\sum_{j \in N}\left[\omega_{j}-E_{j}\right] E_{j}^{p}>0$, reluctance to trade leads to lower overall emission allocations, and hence lower emissions, than in the absence of moral considerations. But how should we interpret the condition $\sum_{j \in N}\left[\omega_{j}-E_{j}\right] E_{j}^{p}>0$ ? It can be interpreted as a weighted average of all permit trades, where permits exporters have $\left[\omega_{j}-E_{j}\right] E_{j}^{p}<0$ and importers $\left[\omega_{j}-E_{j}\right] E_{j}^{p}>0$, and where the weights, $E_{j}^{p}$, are given by the inverse of the slope of the marginal benefit of emissions function (recall that $\left.E_{j}^{p}=1 / B_{j}^{e e}<0\right)$. Thus, in order for $\sum_{j \in N}\left[\omega_{j}-E_{j}\right] E_{j}^{p}$ to be positive, permit exporters should, on average, have smaller absolute values of $E_{i}^{p}$ than permit importers. Note that high absolute values of $B_{i}^{e e}$ (i.e., steep marginal emission abatement cost functions) imply small absolute values of $E_{i}^{p}$. Therefore, the term is positive if permit sellers are predominantly countries with steep marginal abatement cost functions (see the Appendix).

This is not very likely in the Kyoto permit market. Most empirical models predict the contrary, i.e., that low abatement cost countries (i.e., countries with flat marginal benefit functions, $B_{i}^{e}$ ) will export carbon emissions permits, see Böhringer (2002), 
Den Elzen and de Moor (2002) or Eyckmans and Hagem (2008). Therefore, it is more likely that moral concerns would lead to a higher number of permits issued. This means that the solution with moral concerns is likely to to result in higher global emissions than in the absence of those considerations. The result is again due to the over allocation of permits in permit importing countries that follows from Lemma 1.

\subsection{Preferences for abatement at home}

Reluctance to trade is one aspect of a country's moral concerns, but the country could also have preferences for doing the abatement at home. To model this, we assume that identity depends on the relationship between actual emissions and the morally ideal emissions, $e_{i}^{S}$, i.e., the amount of emissions the country thinks it ideally should aim for. This can be specified in the following way:

$$
I_{i}\left(e_{i}, e_{i}^{S}\right)=-\gamma\left[e_{i}-e_{i}^{S}\right]^{2}
$$

As the countries are concerned about the global environment, it is reasonable to assume that the ideal requires substantial abatement. One way to specify this is to follow Brekke et al. (2003) and assume that countries share an ethical view that global social welfare should be maximized. Thus, "ideal" emissions are found by maximizing a utilitarian global welfare function where everybody follows the same general rule, namely to emit the amount that maximizes global welfare:

$$
\max _{\left(e_{1}, e_{2}, \ldots, e_{n}\right)} \quad \sum_{j \in N}\left[B_{j}\left(e_{j}\right)-D_{j}\left(\sum_{k \in N} e_{k}\right)-\gamma\left[e_{j}-e_{j}^{S}\right]^{2}\right]
$$

This gives rise to the following first-order conditions:

$$
B_{i}^{e}\left(e_{i}^{*}\right)-2 \gamma\left[e_{i}^{*}-e_{i}^{S}\right]=\sum_{j \in N} D_{j}^{e}\left(\sum_{k \in N} e_{k}^{*}\right) \quad \forall i \in N
$$

We see that the global welfare function is maximized for $e_{i}^{S}=e_{i}^{*}$. Thus, in this case the identity terms disappears, and the first order conditions equal the well known Samuelson rule (see, e.g., Eyckmans et al., 1993) that defines the first-best allocation of emissions without moral concerns:

$$
B_{i}^{e}\left(e_{i}^{*}\right)=\sum_{j \in N} D_{j}^{e}\left(\sum_{k \in N} e_{k}^{*}\right) \quad \forall i \in N
$$


Having defined the ideal reference level of emissions, we can now write the identity function in the following way, where $e_{i}^{*}$ is considered exogenous:

$$
I_{i}\left(e_{i}, e_{i}^{*}\right)=-\gamma\left[E_{i}(\rho(\boldsymbol{\omega}))-e_{i}^{*}\right]^{2}
$$

Using this function in the maximisation problem defined by (7), we can show that every country will emit more than the "ideal" emissions level.

\section{LEMMA 2}

Even if countries care about their ideal emissions, every individual country will emit more than its ideal: $E_{i} \geq e_{i}^{*}$ and, therefore, total amount of permits allocated will exceed the socially optimal level: $\omega_{N} \geq e_{N}^{*}$.

Proof: Assume, on the contrary, that $\exists i \in N: E_{i}<e_{i}^{*}$. From the strict concavity of the emissions benefit function, it follows that $B_{i}^{e}\left(E_{i}\right)>B_{i}^{e}\left(e_{i}^{*}\right)$. Using the (2) and (17) implies:

$$
\rho\left(\omega_{N}\right)=B_{i}^{e}\left(E_{i}\right)>B_{i}^{e}\left(e_{i}^{*}\right)=\sum_{j \in N} D_{j}^{e}\left(e_{N}^{*}\right)=\rho\left(e_{N}^{*}\right) \Rightarrow \omega_{N}<e_{N}^{*}
$$

At the same time, we can derive:

$$
\begin{gathered}
D_{i}^{e}\left(\omega_{N}\right)+2 \gamma\left[E_{i}-e_{i}^{*}\right] E_{i}^{p} \rho^{\omega}=B_{i}^{e}\left(E_{i}\right)>B_{i}^{e}\left(e_{i}^{*}\right)=\sum_{j \in N} D_{j}^{e}\left(e_{N}^{*}\right) \\
\Downarrow \\
\sum_{j \in N} D_{j}^{e}\left(\omega_{N}\right)-\sum_{j \in N} D_{j}^{e}() \geq D_{i}^{e}\left(\omega_{N}\right)-\sum_{j \in N} D_{j}^{e}\left(e_{N}^{*}\right)>-2 \gamma\left[E_{i}-e_{i}^{*}\right] E_{i}^{p} \rho^{\omega} \geq 0 \\
\Downarrow \\
\omega_{N}>e_{N}^{*}
\end{gathered}
$$

This contradicts the previously established inequality. Thus, for $\forall i \in N: E_{i} \geq e_{i}^{*}$.

Given that every country emits more than the ideal level, the total emissions in the endogenous permit allocation equilibrium will exceed the first-best level: $\omega_{N}>e_{N}^{*}$.

Q.E.D.

As every country always emits more than its ideal, we can easily sign the derivative of the identity function with respect to $\omega_{i}$ : 


$$
\Delta I_{i}=-2 \gamma \rho^{\omega}\left[E_{i}-e_{i}^{*}\right] E_{i}^{p}<0
$$

Based on this, we find that when all countries care about their ideal effort, the endogenous permit allocation equilibrium shifts towards the Pareto efficient first-best allocation of emissions, and they will emit less than without moral concerns.

\section{PROPOSITION 3}

If countries care about their ideal effort, every individual country will emit less without moral concerns and global emissions will be lower.

Proof: Assume, in contrast, that $\omega_{N}^{I}>\omega_{N}^{o}$. Using convexity of the damage functions, it follows that: $\sum_{j \in N} D_{j}^{e}\left(\omega_{N}^{I}\right)>\sum_{j \in N} D_{j}^{e}\left(\omega_{N}^{o}\right)$. As before, using the appropriate first-order conditions for both equilibria, we find:

$$
\rho^{I}-\rho^{o}>\frac{2 \gamma \rho^{\omega}}{n} \sum_{j \in N}\left[E_{j}-e_{j}^{*}\right] E_{j}^{p}>0
$$

Hence, the equilibrium permit price would be higher with moral concerns than without. As the equilibrium price is decreasing in the global permit allocation, we find that $\omega_{N}^{I}<\omega_{N}^{o}$ which contradicts the initial assumption. Therefore, we get $\omega_{N}^{I} \leq \omega_{N}^{o}$.

Also, as the equilibrium price of permits will be higher with moral concerns, every country's representative firm will emit less: $B_{i}^{e}\left(E_{i}^{I}\right)=\rho^{I}>\rho^{o}=B_{i}^{e}\left(E_{i}^{o}\right) \Rightarrow E_{i}^{I}<E_{i}^{o}$ due to concavity of the benefit functions. Q.E.D.

This result is in contrast to the previous conclusion when countries cared about their level of emissions trading and moral concerns could lead to higher global emissions. The reason is that, when countries care about their ideal level of emissions, they feel a warm glow when doing more than what a strictly private cost benefit analysis would prescribe. This shows that it matters what people's concerns are about. If the main concern is distaste against trading emission permits, the environment may be harmed, while if the desire is to reduce emissions at home, the environment will benefit. Note, that this latter conclusion we have assumed that all countries share the same moral standpoint. This will not necessary be the case, and we will comment on that at the end. 


\subsection{Combining both identity effects}

One may argue that people's moral concerns follow both from distaste against trading permits as well as the desire to reduce emissions at home. Thus, it seems appropriate to combine the identity functions from the previous sections. Taken together, the full identity function can be written as:

$$
I_{i}\left(e_{i}, e_{i}^{*}, \omega_{i}\right)=\left\{\begin{array}{lr}
-F-\delta\left[\omega_{i}-E_{i}(\rho(\boldsymbol{\omega}))\right]^{2}-\gamma\left[E_{i}(\rho(\boldsymbol{\omega}))-e_{i}^{*}\right]^{2} \quad \text { if } \quad \omega_{i} \neq E_{i}(\rho(\boldsymbol{\omega})) \\
-\gamma\left[E_{i}(\rho(\boldsymbol{\omega}))-e_{i}^{*}\right]^{2} & \text { otherwise }
\end{array}\right.
$$

The new identity function describes an internal conflict; we can have $e_{i}=e_{i}^{*}$, but still $\omega_{i} \neq e_{i}$, thus doing what is best according to one moral ideal may not fulfill the other.

We can now characterize the full impacts of the moral concerns.

\section{PROPOSITION 4}

If countries are reluctant to trade permits and if they care about abatement at home, global emissions will be lower if either:

- $\quad \sum_{j \in N}\left[\omega_{j}-E_{j}\right] E_{j}^{p}>0$, or

- $\quad$ the concerns about abatement at home are strong enough to compensate the reluctance to trade.

Proof: The proof is trivial by combining PROPOSITION 2 and PROPOSITION 3.

At first sight, one might think it is obvious that moral concerns would lead to lower global emissions. However, PROPOSITION 4 shows that this depends crucially on both the form of the identity function and the balance of power between permit importers and exporters.

As we have argued above, in the case of global climate change, $\sum_{j \in N}\left[\omega_{j}-E_{j}\right] E_{j}^{p}$ is likely to be negative. We can, therefore, conclude that the overall emission level resulting from the international climate negotiations outcome will be lower if there is a relatively strong concern about actual emission levels in all countries. If this concern is weak, or if few countries share this concern, and in addition there is a strong distaste against permit trading, emissions may actually be higher than without any 
concerns about permit trading. Thus, aiming for the good does not always bring the desired outcomes.

\section{Restrictions on permit trading}

As mentioned in the introduction, restrictions of permit trading as found in the Kyoto Protocol and in the ETS, may have been introduced due to reluctance of trading permits. From economic theory we know that restrictions on free permit trading may increase the costs of a treaty; the cost-effective volume may not be within reach. When the costs are higher, the incentives to join the treaty for individual countries will be lower. As a result, the treaty may fail or it may consist of fewer countries. The consequence may be higher global emissions. However, this result follows from standard economic reasoning where the permit allocation is assumed exogenous to each country, and where countries are assumed to have no moral concerns about permit trading. If these assumptions do not hold, will the standard result still prevail?

Over allocation of permits was the reason for higher emissions under moral concerns about permit trading. Thus, we focus on the case with symmetric identity function and where buyers are restricted from buying permits, i.e.,

$$
-\left[\omega_{i}-e_{i}\right]<a\left(\bar{e}_{i}-\omega_{i}\right)
$$

This means that the amount of permit a country can buy should be less than a certain share, $a$, of the necessary abatement. Assume now that this restriction is binding, i.e., countries would like to buy a larger share. In this case we find:

PROPOSITION 5

If countries are reluctant to trade permits, identity is symmetric, and the restriction on buying permits is binding, global emissions will be lower than in the case without such restrictions.

Proof: The proof follows the same line as the proof of Lemma 1. As the first order condition from (11) gives

$$
B_{i}^{e}-D_{i}^{e}=\left[\omega_{i}-E_{i}\right] \underbrace{\left[-\rho^{\omega}+2 \delta\left[1-E_{i}^{p} \rho^{\omega}\right]\right]}_{+},
$$


we see that an effective restriction on buying permits makes the term on the right side less negative. Thus, the marginal benefit will be closer to the marginal damage and there will be less of an over allocation.

Q.E.D.

As there is a restriction on trade, the permit importing countries are less tempted to over allocate emissions compared to the situation without the restrictions on trade. This has a positive effect on the environment. The reduced incentive to over allocate also applies to the strategic trade motive. Thus, the restriction reduces emissions also in absence of moral concerns as long as the emissions allowances are set endogenously. Note, however, that while emissions go down, welfare will also go down, otherwise the restrictions would not have been binding.

Finally, in the case with moral preferences for abating at home, a restriction on permit trading will also has a positive effect on emissions because, also in this case, it reduces the strategic trade motive in permit importing countries.

\section{Discussion and conclusions}

In this paper we have analysed how moral concerns about permit trading affect an endogenous pollution permit trading equilibrium, in which governments choose noncooperatively their national permit allocations, and therefore also the overall environmental objective. There may be different reasons why people and their governments have moral concerns about permit trading. For instance, countries may be reluctant to trade permits because they think it is a way to escape their moral responsibility, or because of the assumed negative consequences the trade may have in developing countries. Hence, both consequentialist and procedural ethics arguments are used to justify limits on access to flexible mechanisms like CDM in the framework of the Kyoto Protocol or the European Emission Trading Scheme.

Given an internationally negotiated permit trading system, we find that moral concerns may increase or reduce global emissions depending on the precise formulation of these concerns. We considered two ways to specify the moral considerations. The first captures the idea that countries might be reluctant to trade. They may have some distaste about trading and would like to avoid it; they consider trading pollution permits not a good thing in itself. If this view is held by permit 
importers only, global emissions will be higher than in an equilibrium without moral concerns. The reason is that permit importers over allocate their domestic firms in order to reduce the amount of permits they have to import. However, if the view is held by both permit sellers and buyers, this result is not necessary true as permit exporters would like to reduce their export. The overall effect on global emissions will depend on the balance of power (more precisely the slope of the marginal abatement cost functions in equilibrium) between permit importers and exporters. But under reasonable assumption, we conjecture that global emissions are likely to increase also in this case.

The second formulation of moral concerns takes into account that countries would like to avoid permit trading as they feel it is their obligation to reduce emissions at home. They take into account what they ideally should do, and would strive to implement the corresponding ideal effort level that requires substantial emission reductions. We show that global emissions will always be lower with this type of moral considerations if all countries follow this rule, as they all have an additional incentive to reduce emissions. However, note that this conclusion dependents on all countries having similar moral concerns. If this is not the case, and only a few countries have this view, the additional abatement would share similarities to unilateral actions taken by one single country. The literature on unilateral actions, such as Hoel (1991), concludes that this policy may affect the outcome of negotiations on emission reductions, and it may very well imply higher total emissions due to carbon leakages. However, if the unilateral action is announced as a commitment to reduce emissions in excess of the outcome of the negotiation, total emissions will likely be lower compared to the case where all countries act selfishly. Hoel and Golombek (2004) also argue that with endogenous technologies and technology diffusion between countries, it is no longer obvious that reduced emissions in some countries will increase emissions in other countries. Thus, the global emission impact from the concern about abatement at home is not clear. However, this shows that moral concerns about permit trading based on the desire to reduce national emissions to what is deemed morally right, does not necessary have a significant impact on global emissions if the concern is shared among a few countries only.

Another interesting result from this study relates to restrictions on permit trading as has been introduced in the Kyoto Protocol and the ETS. While standard economic 
theory suggests that such restrictions may be bad for the environment as they increase the costs of reaching an emission target, and, therefore, the incentive to join a treaty, we show that such restrictions may actually reduce global emissions when governments have moral concerns about trading permits. The reason is that the incentive of permit importers to over allocate domestic industries to reduce permit purchase will be reduced. If restrictions have been introduced due to moral concerns, global emissions will actually be lower, a counterintuitive result compared to standard economic theory. Note that these restrictions will also reduce over allocation due to the strategic permit trading effect. Thus, permit trade restrictions may actually be good for the environment.

Different formulations of the moral concerns than the ones we considered in this paper are of course possible. However, we think that we covered two interesting cases, one that had a negative effect on the environment and one that had a positive effect. But as argued, also in the latter case there may be reasons why global emissions may increase. Therefore, we think this is a rather strong result, even if it is counterintuitive.

There are several ways to follow up this study. A tempting task is to relate the first practical experiences with international emission allocations by governments, such as ETS and the Kyoto agreement, to our theoretical results. In particular, it would be interesting to disentangle moral motivations for imposing limits on access to permit trading from strategic price manipulation motives. Our theoretical results might provide a reference framework to do empirical tests comparing actual negotiation outcomes with results from simulations models of permit trading markets for distinguishing between the different motivations. 


\section{References}

Akerlof, G. and R. Kranton (2000): Economics and Identity, Quarterly Journal of Economics, 115: 716-753.

Akerlof, G. and R. Kranton (2005): Identity and the Economics of Organizations, Journal of Economic Perspectives, 19: 9-32.

Andreoni, J. (1990), Impure altruism and donations to public goods: a theory of warm-glow giving, The Economic Journal, 100: 464-477.

Bénabou, R. and J. Tirole (2007): Identity, Dignity and Taboos: Beliefs as Assets, Discussion Paper No. 2583, January 2007, IZA Bonn.

Bergstrom, T., Blume, L., and Varian, H. (1986), On the private provision of public goods, Journal of Public Economics, 29: 25-49.

Barrett, S. (2005): The theory of international environmental agreements, Chapter 28 in K.-G. Mäler and J. R. Vincent (eds.): Handbook of Environmental Economics, Volume 3: 1457-1516. Elsevier B.V.

Böhringer, C. (2002): Climate Politics from Kyoto to Bonn: From Little to Nothing?, The Energy Journal, 23: 51-73.

Brekke, K. A, S. Kverndokk and K. Nyborg (2003): An economic model of moral motivation, Journal Public Economics, 87: 1967-1983.

Carbone, J.C., C. Helm and T.F. Rutherford (2009): The Case for International Emission Trade in the Absence of Cooperative Climate Policy, Journal of Environmental Economics and Management. Forthcoming

den Elzen, M.G.J. and de Moor, A.P.G. (2002), Analyzing the Kyoto Protocol under the Marrakesh Accords: Economic Efficiency and Environmental Effectiveness, Ecological Economics, 43: 141-158.

Ellerman, D. and S. Wing (2000), Supplemantarity: An Invitation for Monopsony, The Energy Journal 21(4): 29-59.

Eyckmans, J., S. Proost and E. Schokkaert (1993): Efficiency and Distribution in Greenhouse Negotiations, Kyklos 46(3): 363-397.

Eyckmans, J., and E. Schokkaert (2004): An "Ideal" Normative Theory for Greenhouse Negotiations?, Ethical Perspectives, 11(1): 5-22.

Eyckmans, J., and C. Hagem (2008), The European Union's potential for strategic emissions trading in a post-Kyoto climate agreement, Statistics Norway, Discussion Papers no. 530.

Fiske, A. P. and P. E. Tetlock (1997): Taboo Trade-offs: Reactions to Transactions That Transgress the Spheres of Justice, Political Psychology, 18(2): 255-297.

Frank, R. H. (1985): Choosing the Right Pond: Human Behavior and the Quest for Status, Oxford University Press

Golombek, R. and M. Hoel (2004): Unilateral Emission Reductions and CrossCountry Technology Spillovers, Advances in Economic Analysis \& Policy, vol 4 , no. 2 , article 3 . 
Golombek, R. and M. Hoel, (2005): Climate Policy under Technology Spillovers, Environmental and Resource Economics, 31(2): 201-227.

Goodin, R. E. (1994): Selling Environmental Indulgences, Kyklos, 4: 573-596.

Hahn, R. W. (1984): Market Power and Transferable Property Rights, The Quarterly Journal of Economics 99(4): 753-765.

Helm, C. (2003): International emissions trading with endogenous allowance choices, Journal of Public Economics, 87: 2737-2747.

Hoel, M. (1991): Global Environmental Problems: The Effects of Unilateral Actions Taken by One Country, Journal of Environmental Economics and Management, 20: 55-70.

Holsmark, B.J. and D.E. Sommervoll (2008): International emissions trading in a noncooperative equilibrium, Discussion Papers 542, Statistics Norway.

Kverndokk, S. (1995): Tradeable $\mathrm{CO}_{2}$ Emission Permits: Initial Distribution as a Justice Problem, Environmental Values, 4(2): 129-48.

Kverndokk, S. and A. Rose (2008): Equity and justice in global warming policy, International Review of Environmental and Resource Economics, 2(2): 135176.

Montgomery, D. W. (1972): Markets in Licenses and Efficient Pollution Control Programs, Journal of Economic Theory, 5: 395-418.

Pogge, T. W. (1989): Realizing Rawls. London: Cornell University Press.

Rauscher, M. (2006): Voluntary Emission Reductions, Social Rewards, and Environmental Policy, CESifo Working Paper No. 1838, CESifo Group Munich.

Rosendahl, K.E. and J. Strand (2009): Simple Model Frameworks for Explaining Inefficiency of the Clean Development Mechanism, Policy Research Working Paper 4931, The World Bank, Washington, D.C.

Roth, A. E. (2007): Repugnance as a Constraint on Markets, Journal of Economic Perspectives, 21(3): 37-58.

Schmalensee, R., P.L. Joskow, A.D. Ellerman, J.P. Montero and E.M. Bailey (1998): An Interim Evaluation of Sulfur Dioxide Emissions Trading, The Journal of Economic Perspectives, 12: 53-68.

Siebert, H. (1992): Economics of the Environment, $3^{\text {rd }}$ ed., Berlin: Springer.

Stavins, R. N. (1995): Transaction Costs and Tradeable Permits, Journal of Environmental Economics and Management, 29: 133-148.

Tannenwald, N. (1999): The Nuclear Taboo: The United States and the Normative Basis of Nuclear Non-Use, International Organization, 53(3): 433-468.

Zeliner, V. (1999): Morals and Markets: The Development of Life Insurance in the United States. New York: Columbia University Press. 


\section{Appendix: The benefit function}

A general abatement cost function frequently used in the literature is:

$$
C(a)
$$

Abatement, $a$, is defined as the difference between the business-as-usual emissions $\bar{e}$ and actual emissions $e$, i.e., $a=\bar{e}-e$. Where business as usual (BAU) emissions are defined as emissions in absence of environmental regulations.

It is usually assumed that this cost function has the following properties (see, e.g., Golombek and Hoel, 2005):

$$
C^{a} \equiv \frac{\partial C}{\partial a}>0 ; \quad C^{a a} \equiv \frac{\partial^{2} C}{\partial a^{2}}>0
$$

Abatement costs are defined as the difference in benefits between the business-asusual and actual emission level

$$
C(a)=C(\bar{e}-e)=B(\bar{e})-B(e)
$$

which defines a benefit function:

$$
B(e)=B(\bar{e})-C(a)
$$

We assume that benefits of emissions are such that an interior solution to the firm's maximization problem always exists. Thus,

$$
\begin{aligned}
& B^{e} \equiv \frac{\partial B(e ; \beta)}{\partial e}=C^{a}>0 \\
& B^{e e} \equiv \frac{\partial^{2} B(e ; \beta)}{\partial e^{2}}=-C^{a a}<0
\end{aligned}
$$

